\title{
Research on the Mobile Capability of Basketball Players' Gait Based on SPSS Software
}

\author{
Hailong Cen
}

Department of PE Teaching, Inner Mongolia Normal University, Hohhot 010022, Inner Mongolia, China

\begin{abstract}
Objective: to analyze the training student footwork potential, understand status of students in the footsteps of horizontal movement, to arrange student footwork training content. Methods: using SPSS for statistics and analysis. Results: according to the structural factors of mobile ability, combined with the basketball court, make full use of the actual site boundaries and game design basketball athletes footwork testing method, test results show that it has high reliability and validity. The main factors and specific indexes of the students' ability to move the students' gait were selected.. Conclusion: practical application results show that the mobile ability evaluation method is more effective and reliable can be used for monitoring and evaluation of basketball player in mobile ability of comprehensive development level, and the physical development of equilibrium, so as to training plan formulation, training methods of the choice to provide scientific basis.
\end{abstract}

Keywords: Basketball players, gait movement, model evaluation, SPSS.

\section{INTRODUCTION}

As the most basic step of mobile technology of basketball, basketball is the foundation and condition of other techniques, it is on the basketball players, transport, transfer, the defense technology plays an important role "at present, basic basketball training in China too quick, not as the basic skills practice, resulting in the basketball enlightenment stage do, have to put in the university stage to complete the basic skills, excellent will determine its future progress and development of [1]., how to improve the training of footwork effect, to achieve control of college basketball players in the training process, must grasp the accurate feedback information, choose the appropriate training methods, and moving ability of basketball players the measurement and evaluation method is to master the quantitative feedback information, through quantitative analysis of physical factors structure and judgment ability of dynamic shift fast pace mastery of technology, to provide mobile training process control for coaches.

Mobile is refers to in the basketball game, players in order to change the position, direction, speed and strive for high and obtain favorable opportunity and space, so as to achieve tactical purpose to adopt the reasonable pace movement in general. According to the types and connection of basketball technology actions can also be divided into to get rid of the mobile, moved the ball, shooting mobile, mobile defense, rebounding mobile; accordance with the pace of action and assigned to running, cross, jump, turn all kinds of footwork. And influence factors of these steps are more intuitive, which will affect factors of college basketball players' ability to move into foot movement of influence factors, such as: running speed quality), cross (speed, power quality), jump (jump character), turns, sensitive and coordinating quality) [2]. According to the actual situation of mobile players in basketball game, players in the basketball match actual mobile route and method simulation, design mobile comprehensive ability test method, combined with greater correlation factor influence on the movement of the athlete, footwork performance evaluation model was established, to provide services to the practical training.

\section{RESEARCH OBJECT AND METHOD}

\subsection{Research Object}

The design and practice of the evaluation model for the athletes' movement ability of the basketball players in the Super League of China.

Survey: Central South University, Shanghai Jiaotong University, Wuhan University of technology, Ningbo University, Tianjin Polytechnic University, Huazhong University of science and technology, Xiamen University, Northeast Normal University 8 in college basketball athlete in the competition of China University Basketball Super League men.

\subsection{Research Method}

Expert questionnaire and recovery, modeling index solicit expert opinion, and statistics the experts' opinions, which leads to the conclusion that the chosen with index 1 and invited experts on the selected indicators, using 1,2, 3, 4 and 5 of 5 grade method score \# statistics all the experts scores of all the indicators selected and calculated the average score of each indicator, for average score greater than 4 
indicators will be screened out of standby. Statistical optimization and index for screening again, Experts $(5 \sim 45 \mathrm{~m})$ concluded that the comprehensive results, according to the research needs, the index merger measures: the direction of movement (before and after, left, right, oblique); moving distance; mobile route (linear, slash, curve); the moving footwork (TIC, cross, mats, and, running, jumping, action, stop, side, back, turn). The questionnaire reliability and validity test: we study the same rate to test the questionnaire validity, test-retest reliability coefficient of 0.88 and expert of up to more than $90 \%$ recognition rate. Thus it can be seen that the questionnaire is designed in accordance with the statistical requirements. Data collected from the questionnaire survey, and the data were processed and analyzed by SPSS10.0 statistical software.

\section{DESIGN OF TEST METHOD FOR MOBILE CAPA- BILITY}

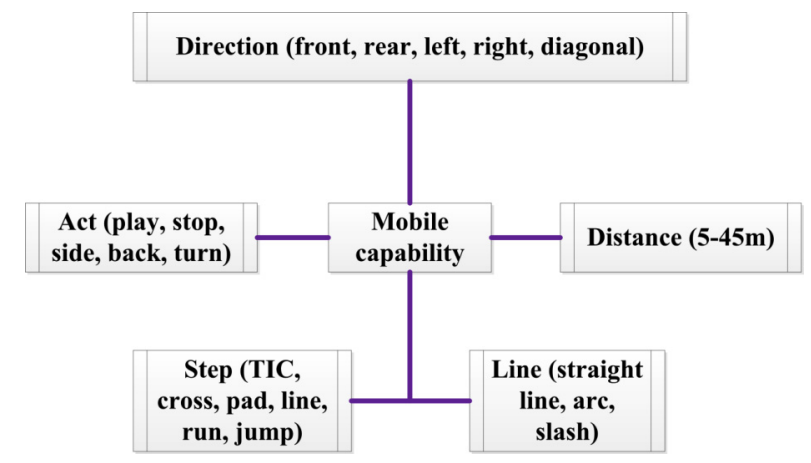

Fig. (1). Basic elements of mobility.

Footwork basketball player is composed of power, coordination, flexibility, flexibility and balance etc. constitute elements of a complex action system between various factors can promote each other, and can contain each other, not only can make up for each other, but also to restrict each other, not only have the overall functional capacity also, a single factor. The action reflects a variety of factors common role specific [3]. as shown in Fig. (1) shows, the ability to move the basic structural elements including movement (start, stop, turn, turn), moving direction (forward, backward, left, right, transverse, oblique, moving line () straight line, arc, line) and footwork (running, jumping, sliding, stepping) [4].

Comprehensive testing method for design of basketball footwork. According to the actual situation of the game and players can travel on the move route, direction, action elements, and methods of using the design as far as possible to suit one's measures to local conditions, the basketball court, can response to exercise the truth, but also reflects the ability of mobile players. Players face the right touchline site is located at the end line at the end of 1 , starting $2 \rightarrow$ speed (line stop left front turn) $3 \rightarrow$ step $4 \rightarrow$ end stop change to $5 \rightarrow$ step $6 \rightarrow$ feet hit the sideslip stop jump hit the basket plate $7 \rightarrow$ Step $8 \rightarrow$ line cross stop $9 \rightarrow$ back run $10 \rightarrow$ line after a sudden stop turn $\rightarrow$ arc running sideways $\rightarrow$ stop foot jump hand slap rebounds over [5] (Fig. 2).

Test method of reliability test is mainly determine the feasibility of the designed mobile ability test method, reliability reflect reliability test method and in the test error of size, in test with expert investigation method of the test method is feasible, basic feasible, not feasible "evaluation of three dimensions, to basketball coaches and experts issued a total of 25 questionnaires, 25 copies were returned, 23 copies of valid questionnaires, effective recovery rate of $92 \%$. It was considered that 17 people, $73.9 \%$ of the professors, and 5 of the associate professors, accounted for $21.7 \%$. From the expert thinks that the design of the comprehensive test method of the mobile capability is feasible. Then to test the validity test, obtained the test-retest reliability coefficient $(\mathrm{r}=0.837)$ (Table 1). The results of the survey show that is true and reliable.

Test the validity of the method is tested: please the coach of the team from their training athlete's ability to move divided into five grades, the grade as criterion, and then use the above method to test mobile achievement of the students, and with coach's subjective evaluation of correlation analysis, the etc. level method to calculate the validity Coefficient $r=1-6 \sum d^{2} / n\left(n^{2}-1\right)$.

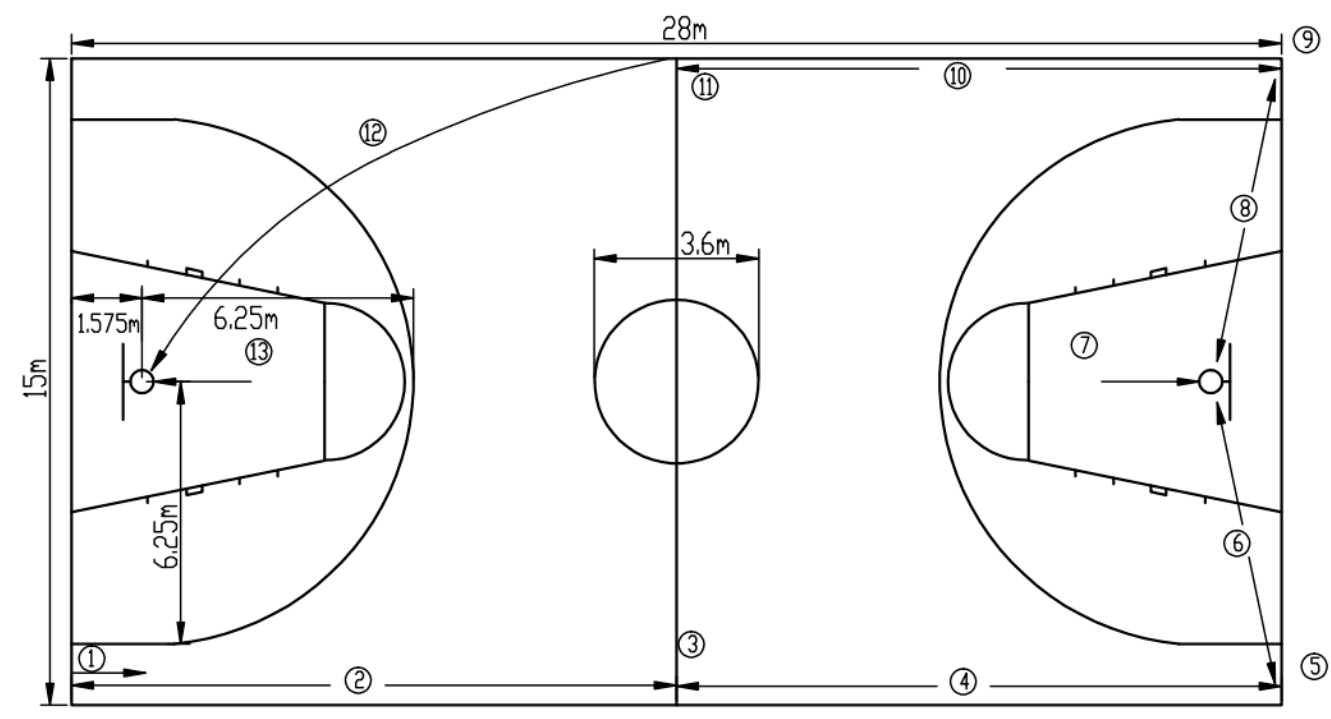

Fig. (2) A comprehensive test method for the moving capability of basketball players' gait. 
Table 1. Reliability test of test method.

\begin{tabular}{|c|c|c|c|}
\hline Inspection Method & Calculation Method & Reliability Coefficient $\mathbf{r}$ & Reliability Level \\
\hline \hline Another method & $\begin{array}{c}\text { Product difference correlation } \\
\text { coefficient method }\end{array}$ & $\mathrm{R}=0.837$ & Acceptable \\
\hline
\end{tabular}

Table 2. The validity of the test method.

\begin{tabular}{|c|c|c|c|c|c|c|c|}
\hline $\mathrm{r}=0.897$ & $\mathrm{r}=0.786$ & $\mathrm{r}=0.664$ & $\mathrm{r}=0.842$ & $\mathrm{r}=0.735$ & $\mathrm{r}=0.832$ & $\mathrm{r}=0.705$ & $\mathrm{r}=0.812$ \\
\hline $\mathrm{P}<0.01$ & $\mathrm{P}<0.01$ & $\mathrm{P}<0.05$ & $\mathrm{P}<0.01$ & $\mathrm{P}<0.01$ & $\mathrm{P}<0.01$ & $\mathrm{P}<0.01$ & $\mathrm{P}<0.01$ \\
\hline
\end{tabular}

Table 3. Reliability and validity of the test results.

\begin{tabular}{|c|c|c|c|}
\hline Inspection Items & Reliability Coefficient $\mathbf{r}$ & Reliability Level & $\begin{array}{c}\text { Correlation Analysis of Mobile } \\
\text { Capability }\end{array}$ \\
\hline \hline Squat & $\mathrm{r}=0.737$ & Acceptable & $\mathrm{P}<0.05$ \\
\hline $30 \mathrm{~m}$ run & $\mathrm{r}=0.975$ & Very nice & $\mathrm{P}<0.01$ \\
\hline The run-up height & $\mathrm{r}=0.675$ & Acceptable & $\mathrm{P}<0.05$ \\
\hline $100 \mathrm{~m}$ run & $\mathrm{r}=0.714$ & Acceptable & $\mathrm{P}<0.05$ \\
\hline Vertical jump & $\mathrm{r}=0.815$ & Quite well & $\mathrm{P}<0.01$ \\
\hline $5 * 10 \mathrm{~m}$ reentry run & $\mathrm{r}=0.867$ & Very nice & $\mathrm{P}<0.05$ \\
\hline $800 \mathrm{~m}$ run & $\mathrm{r}=0.621$ & Unacceptable & $\mathrm{P}<0.05$ \\
\hline Sit ups & $\mathrm{r}=0.655$ & Acceptable & $\mathrm{P}<0.01$ \\
\hline Standing long jump & $\mathrm{r}=0.914$ & Very nice & \\
\hline
\end{tabular}

$\mathrm{D}$ is grade difference, $\mathrm{n}$ samples and the results were correlation test. From Table 2 shows, student test results and teachers' subjective evaluation results significantly correlated, that the test method can reflect the students in the footsteps of the ability to move.

\section{RESULTS AND ANALYSIS}

\subsection{The Main Factors Affecting the Students' Ability to Move and the Selection of Specific Indicators}

According to the structural characteristics of the footwork, primaries and corresponding logical relationship of influencing factors: squat, $30 \mathrm{~m}$ running, Mogao run-up, $100 \mathrm{~m}$, standing vertical jump, $5 * 10 \mathrm{~m}$ shuttle run, $800 \mathrm{~m}$ run, sit ups, standing long jump out of a total of nine indicators, testing nine indicators of achievement.

The reliability index of the test method, obtained the testretest reliability coefficient $r$, which is two times with the test indicators, and calculated the intraclass correlation coefficient of two test results. If the reliability coefficient $r$ value, squat, run-up height, $100 \mathrm{~m}$ run, sit ups in $0.65 \sim 0.75$ is acceptable in situ; in the vertical jump 0.75 0.85 quite well; $30 \mathrm{~m}$ running, $5^{*} 10 \mathrm{~m}$ running, standing long jump in more than 0.85 very good [7]. The test results showed that, the reliability coefficients were in the acceptable range, test project indicators and students moving to a significant or very significant correlation. Force level indicates that the test indexes and footwork the ability of highly correlated, high availability. Nine test indicators of primary reliability and validity test, the test results are shown in Table 3.

This study is a non - explicit "identification mark" variable, the application factor analysis method, to find out the load factor of the common factor of controlling all the variables as the typical test index [8]. For the selected 9 indicators squat, $30 \mathrm{~m}$ running, running up to touch, $100 \mathrm{~m}$ running, standing vertical jump, $5^{*} 10 \mathrm{~m}$ running, $800 \mathrm{~m}$ running, sit ups, standing long jump, they reflect the level of footwork, but these nine indicators are used for testing, will inevitably increase the difficulty of the work, reduce the work efficiency. So we must further selection of the nine indicators, selected the typical index of one of the most representative, we can reduce the steps and links in the actual operation, but also can achieve our purpose, fully reflect the true strength. The team move was calculated by using SPSS10.0 statistical software, establish the factor model, and test, test results show, significant factor model to achieve our research requirements, show that the index selection is desirable.

From the above analysis result, the cumulated variance contribution ratio of the three public factor of $85.327 \%$, according to the cumulated variance contribution ratio of the common factor to determine the public factor, we selected the number to three factors, the spinning larger load factor 
Table 4. Reliability and validity of the test results.

\begin{tabular}{|c|c|c|c|}
\hline Index & 30m Run & Standing Long Jump & 5*10m Reentry Run \\
\hline \hline Weight T & 0.435 & 0.337 & 0.228 \\
\hline Sort & 1 & 2 & 3 \\
\hline
\end{tabular}

Table 5. The reliability test of the weight value of the typical indexes.

\begin{tabular}{|c|c|c|c|}
\hline Index & 30m Run & Standing Long Jump & 5*10m Reentry Run \\
\hline \hline Weight q & 0.435 & 0.337 & 0.228 \\
\hline Judgment matrix consistency C & 0.0004 & & \\
\hline Mean random consistency R & 0.48 & & \\
\hline $\begin{array}{c}\text { Random consensus ratio } \\
\mathrm{r}=\mathrm{C} / \mathrm{R} \approx 0.0008<0.05\end{array}$ & & & \\
\hline
\end{tabular}

index has three, respectively represent the speed quality, explosive force, response speed and physical quality of the $30 \mathrm{~m}$; On behalf of agility, flexibility, coordination, balance and explosive physical qualities such as a reverse layup $5 *$ $10 \mathrm{~m}$; Represent relative strength, power, flexibility, coordination and so on physical quality of standing long jump. Three typical indicators represent the meaning is: $30 \mathrm{~m}$ running in basketball players move in, lateral, retreat, cross, jump and start, turned to a straight line. Such as slash. Arc movement in a reverse layup $5 * 10 \mathrm{~m}$, mainly reflected in basketball players move in starting, stop, and turn and, in turn, lateral, stride, stepping straight, oblique line of moving. [9] standing long jump, the basketball player in the mobile mainly reflects in starting, accelerate, jump, turn, etc.

$30 \mathrm{~m}$ running and exhumation of the $5^{*} 10 \mathrm{~m}$ run and standing jump three qualities determine athletes footwork. Using factor analysis method to calculate the weight of index test, much weight level reflect the influence and function of the index sizes in footwork test, were normalized and get the weight of each index and the typical indicators of footwork influence ranking (Table 4).

Reliability test of the index weight, mainly calculated the value of random consistency ratio $\mathrm{R}, \mathrm{r}$ were then compared with values of less than 0.05 has high reliability, and vice versa is not desirable. $\mathrm{R}$ can do judgment matrix consistency $\mathrm{C}$ and average uniform random $\mathrm{R}$ ratio (Table 5).

\subsection{Establish Regression Equation}

In SPSS10.0 software operating system, the footwork (y) for variables and $30 \mathrm{~m}$ run (the independent variable $\mathrm{x} 1$ ), $5 * 10 \mathrm{~m}$ shuttle run (the independent variable $\mathrm{x} 2$ ), standing long jump (the independent variable $\mathrm{x} 3$ ) enter the score calculation for variables and the three variables of multiple regression equation. Non standardized regression equation $Y=9.571+0.563 X 1+0.416 X 2-0.381 X 3$. test results $\mathrm{t}$ respectively $\left(2.835,2.451,-2.093\right.$, significant $\mathrm{sig} \geq_{0.005}$, variance analysis results show: regression equation significantly higher.

\subsection{Goal Pattern and Evaluation Method and Standard Establishment}

The human body is an organic whole, is a complete system. Therefore, all kinds of sports quality of athletes is a mutual influence \# depend on each other, there are a lot of transfer between sports quality phenomenon. To establish quantitative index system is mainly on the development process of footwork ability is based on the premise that to a representative, to reflect the characteristics of basketball sports; In line with the surveying effective, reliable, objective three principles; Method is simple, the result can use quantity and conforms to the characteristics of the athletes said [10-12]. Basketball athletes footwork ability training and improve, mainly on scientific training method, training is a dynamic process, the training methods in the dynamic process is adjusted ceaselessly in changing, but the change and adjustment is not blind, is in understanding and mastering the athletes in the past, present and future, also is the foundation of the athletes in the past, the present situation of the training and the future forecast, on the basis of only in this way can accomplish know fairly well, target, improve the training efficiency. So it is necessary to establish the athlete mobility quantitative index system, therefore, analyzed the check items and the distribution characteristics of fast moving performance, the $\mathrm{K}-\mathrm{S}$ inspection confirmed that the data index is normal distribution, based on index of sample mean, standard deviation, the optimized regression prediction mathematical equations for calculation, the effect between each factor and the footwork ability to integrate (Table 6).

The ability to move the basketball players of good and bad, strong and weak, we cannot judge, because the comprehensive ability to move, $30 \mathrm{~m}$ running, $5 * 10 \mathrm{~m}$ running, standing long jump of quality is not the same, the test indexes of different test indicators, size, speed, distance units are not the same, we are unable to make direct comparisons only by subjective judgment, comparison and judgment, will inevitably be disturbed by various factors, make objective evaluation "in order to facilitate the process of teaching evaluation in different testing items are compared with each 
Table 6. Quantitative indicator system for the development of mobile capability.

\begin{tabular}{|c|c|c|c|}
\hline Comprehensive Test & $5 * 10 \mathrm{~m}$ Movement & 30m Run & Standing Long Jump \\
\hline 14.675 & 6.346 & 3.125 & 3.142 \\
\hline 15.446 & 6.685 & 3.154 & 2.957 \\
\hline 15.753 & 7.246 & 3.262 & 2.883 \\
\hline 15.872 & 7.425 & 3.324 & 2.774 \\
\hline 16.243 & 7.632 & 3.753 & 2.698 \\
\hline 16.532 & 7.964 & 3.842 & 2.625 \\
\hline 16.635 & 8.256 & 3.945 & 2.583 \\
\hline 17.352 & 8.532 & 4.134 & 2.524 \\
\hline 17.642 & 8.632 & 4.224 & 2.472 \\
\hline 17.947 & 8.852 & 4.453 & 2.424 \\
\hline
\end{tabular}

other, and can reflect the basic law of the development of motor ability of each test project, we will integrate the mobile ability, $30 \mathrm{~m}$ running, $5 * 10 \mathrm{~m}$ running, standing long jump performance is quantified, finally reflected through a specific fraction, so we are on every basketball player can objectively compare. Using standard method, the test scores of the detection index is transformed into a fraction of the units of measurement, and carries on the comparison and judgment. Through K-S test confirm the sample data obey the normal distribution in this fraction.

Q standard:

$$
\begin{aligned}
& T=(70+(\bar{X}-X) \times 10 / S) \times \text { High quality index } \\
& T=(70+(\bar{X}-X) \times 10 / S) \times \text { High quality index }
\end{aligned}
$$

Calculation sample data set the score table and exhumation of the $5^{*} 10 \mathrm{~m}$ dynamic, $30 \mathrm{~m}$ run, comprehensive test of the unit is "s"; standing long jump of the unit is "m". Basketball athletes footwork is by the explosive force, coordination, flexibility, flexibility and balance of various elements constitute a complex footwork system, between the various factors can promote each other and mutual restraint, can complement each other, but also can restrict each other, both the overall functional capacity reflected, the influence of single factor. Therefore, in the construction of the evaluation model, it is not only to consider the comprehensive quality, but also to consider the outstanding quality. So the $5 * 10 \mathrm{~m}$ shuttle $30 \mathrm{~m}$ run, standing long jump, 3 qualities and comprehensive test methods, establish the standard score scale.

\section{APPLICATION OF MOBILE CAPABILITY EVALUATION MODEL}

In the mobile ability evaluation index system, evaluation model and evaluation standard is determined, can move ability evaluation of basketball players. In this paper, the use of the model and the method of Wuhan science industry and trade university men's basketball team of 12 members were assessed.

\subsection{Evaluation Method}

In basketball sports training practice, because of the athlete's quality, ability, congenital condition is different, each player has its own advantages and disadvantages, therefore, every athlete will try to foster strengths and circumvent weaknesses, formed its own unique style and characteristics of "made it impossible for the quality at the same level and balanced development, at the same time because of the quality between can into each other and compensate each other, so, in the same quality level athletes have different types" that is, within a certain range, the height of the development of some quality, can be made of the development of other qualities. Among quality can promote each other, but also contain, can convert, and compensation. Quick footwork is the comprehensive reflection of the development level of a variety of quality, therefore, in the evaluation of fast moving training level, must consider the quality of comprehensive development level. According to the basic theory of sports training and the basic principle of normal distribution, made a comprehensive mobile ability and basic physical quality, individual physical quality compared with the average fitness of basic principles of evaluation and judgment standard, you can fast find the weak link of athletes, coaches and on this basis, the fast moving ability training for athletes clear direction, target, grasp key, methods for planning, etc.

If the comparison between $M$ and $X, X-5 \geq M \leq X+5$ is the stage of teaching and training tasks to improve footwork techniques and physical quality average level; $\mathrm{M}<\mathrm{X}-5$ is the stage of teaching and training tasks to improve footwork techniques; $\mathrm{M}<\mathrm{X}-10$ should improve footwork technology is focused on determining the stage of teaching and training tasks; $\mathrm{M}>\mathrm{X}+5$ should determine the stage of teaching and training the task for improving the physical quality level of general average; $\mathrm{M}>\mathrm{X}+10$ should focus on improving the physical quality of the average level to determine the stage teaching training task. If X1, X2, X3 and X, X1, X2, X3 values were between $\mathrm{X} \pm 5$ should determine the stage teaching and training tasks for synchronization to improve the physical quality level; X1 X2, X3, the value is less than X-5, you 
should set the stage for general training tasks to improve the physical quality level; $\mathrm{X} 1, \mathrm{X} 2, \mathrm{X} 3$ value is less than $\mathrm{X}-10$ should focus on improving the physical quality level to determine the stage teaching training task. This information is the ability to move the team training plan formulation and revision on the basis of teaching.

\subsection{Results Analysis and Evaluation}

A The values of $\mathrm{M}>\mathrm{X}+5, \mathrm{X} 1, \mathrm{X} 2, \mathrm{X} 3$ were located in $\mathrm{X}+$ 5, and the level of physical quality was improved, and the level of physical fitness was improved.

$\mathrm{B} X 1$, the $\mathrm{M}<\mathrm{X}-5$ value is less than $\mathrm{X}-5$, the technology of the step movement is improved, and the level of the sensitivity and coordination level is generally improved.

C X3, the $\mathrm{X}-5>=\mathrm{M}<=\mathrm{X}+5$ value is less than $\mathrm{X}-5$, while improving the skill of the foot movement and the average level of the body quality, the emphasis is to improve the level of the explosive quality.

$\mathrm{D}$ The values of $\mathrm{X}-5>=\mathrm{M}<=\mathrm{X}+5, \mathrm{X} 1, \mathrm{X} 2$, and $\mathrm{X} 3$ were located in $\mathrm{X}+$ 5, and the average level of the skill and the physical quality of the feet was improved.

$\mathrm{E} X 1, \mathrm{X}-5>=\mathrm{M}<=\mathrm{X}+5$ value is equal to $\mathrm{X}-5$, while improving the skill of the pace and the average level of the body quality, it should be determined that the training task of the stage is to improve the level of the physical quality.

$\mathrm{F} X 1$, the $\mathrm{X}-5>=\mathrm{M}<=\mathrm{X}+5$ value is less than $\mathrm{X}-5$, while improving the pace of the action and the body quality of the average level of the average, generally improve the level of sensitivity and coordination.

$\mathrm{G} \mathrm{X1}$, the $\mathrm{M}<=\mathrm{X}-10$ value is less than $\mathrm{X}-5$, the key to improve the pace of the technology, generally improve the level of sensitivity and coordination.

$H X 1$, the value of $M>=X+10$ is less than $X-10$, and the key is to improve the quality of the body, and the key is to improve the level of sensitivity and coordination.

I The values of $\mathrm{M}>\mathrm{X}+5, \mathrm{X} 1, \mathrm{X} 2, \mathrm{X} 3$ were located in $\mathrm{X}+$ 5, and the average level of the physical quality was improved, and the quality of the body was improved simultaneously.

$\mathrm{J} X 1$, the value of $\mathrm{M}>=\mathrm{X}+10$ is equal to $\mathrm{X}-5$, and the key is to improve the quality of the body, especially to improve the level of the quality of the sensitive coordination.

$\mathrm{K} \mathrm{X} 3$, the value of $\mathrm{X}-5>=\mathrm{M}<=\mathrm{X}+5$ is less than $\mathrm{X}-5$, and the average level of the action technique and body quality is improved, and the quality of the explosive force is generally improved.

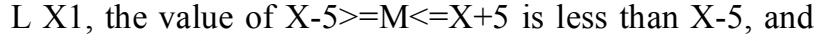
the average level of the skill of the foot movement and the body quality is improved, and the level of the sensitive coordination is generally improved.

\section{CONCLUSION}

Basketball athletes footwork is the explosive force, coordination, flexibility, flexibility and balance of various elements constitute a complex footwork system, between the various factors can promote each other and mutual restraint, can complement each other, and to restrict each other, both the overall functional capacity of reflected, but also the influence of single factor. When the evaluation model is constructed, the quality should be considered and the outstanding quality should be considered.. Design of comprehensive test methods of basketball athletes footwork, according to the actual situation of the game and the players in the mobile can travel route, orientation, action and method factors, adjust measures to local conditions, as far as possible the use of basketball venue design, can motor responses match the real situation, and can reflect the players the ability to move. By the method of factor analysis, screened the main factors influence on students footwork, respectively represent the speed quality, explosive force, reaction speed and other physical quality $30 \mathrm{~m}$ run on behalf of agility, flexibility, coordination, balance and power of physical quality $5 * 10 \mathrm{~m}$ running and represents the relative strength, explosive force, flexibility the coordination of physical quality, standing long jump, so will the $5 * 10 \mathrm{~m}$ shuttle run, $30 \mathrm{~m}$ run, standing long jump 3 qualities and comprehensive test methods, establish the evaluation index system of mobile ability, evaluation model and evaluation standard to establish the standard score scale, using the model and method of 12 members of the Wuhan University of Technology men's basketball team conducted evaluation the result of evaluation, and the use of sports.

The training of the fast moving ability of the direction of the training, determine the target, grasp the key, looking for methods, plan, etc. Use results show that mobile ability evaluation method is reliable and effective for monitoring and evaluation of basketball player in mobile ability and quality of comprehensive development level, and the physical development of the equilibrium condition and improve the training of college basketball players the ability to move and training.

\section{CONFLICT OF INTEREST}

The author confirms that this article content has no conflict of interest.

\section{ACKNOWLEDGEMENTS}

Declared none.

\section{REFERENCES}

[1] L. Xinzheng, "There are basketball physical training in China and Countermeasures against the problems," Journal of Physical Education, vol. 5, pp. 114-116, 2006.

[2] W. Yan, "The teaching mode of the volleyball pace of college sports volleyball professional volleyball," Journal of Wuhan Sports Institute, vol. 12, pp. 12-16, 2005.

[3] H. Jian, and Z. Liqing, "Research on the physical quality training of basketball players to explore," Journal of Capital Institute of Physical Education, vol. 2, pp. 127-130, 2006.

[4] L. Jingyong, Y. Hongyan, Z. Chun, and Z. Yu, "New train of thought for physical training of athletes - core stability training," Journal of Tianjin University of Sport, vol. 2, pp. 128-130, 2008.

[5] G. Shanguang, "Physical training problem of our country and the theory," Sports Journal, vol. 1, pp.88-91, 2008.

[6] H. Guomin, "Applied statistical methods and essentials," Wuhan: Wuhan SPSS press, 2002:15-25.

[7] L. Dan, "The ball movement training concept critique," Beijing Sport University press, 2006. 
[8] W. Jianmin, "Research on the special skill training mode of the juvenile male volleyball players' special skill to study," Sports Science and Technology of China, vol. 1, pp. 60-65, 2006.

[9] Pan Li. Characteristics and research status of the special sensitive quality of Ping Li Ping Li. Journal of Shandong Sports Institute, 2000, (3): 47-51.
[10] L. Xinggang, "The research on the index and the evaluation criteria of the juvenile basketball players in our country," Capital Institute of Physical Education, 2013.

[11] Z. Yating, "A study on the quality of sports for the badminton players in Hubei province," Journal of Wuhan Sports Institute, vol. 1, pp. 33-37, 2007.

[12] L. Zhiying, An empirical study of ball physical quality of students major," Journal of Wuhan Sports Institute, vol. 2, pp. 27-29, 2008.

Received: June 10, 2015

Revised: July 29, 2015

Accepted: August 15, 2015

(C) Hailong Cen; Licensee Bentham Open.

This is an open access article licensed under the terms of the (https://creativecommons.org/licenses/by/4.0/legalcode), which permits unrestricted, noncommercial use, distribution and reproduction in any medium, provided the work is properly cited. 